OPEN ACC (

\title{
Protected area use by two sympatric marine predators repopulating their historical range
}

\author{
Marcus Salton ${ }^{1,6, *}$, Matt $\operatorname{Carr}^{2,7}$, L. Max Tarjan ${ }^{3,8}$, Justin Clarke $^{1}$, Roger Kirkwood ${ }^{4,9}$, \\ David Slip ${ }^{1,5}$, Robert Harcourt ${ }^{1}$ \\ ${ }^{1}$ Department of Biological Sciences, Macquarie University, North Ryde, New South Wales 2109, Australia \\ ${ }^{2}$ Department of Primary Industries, Jervis Bay Marine Park, New South Wales 2540, Australia \\ ${ }^{3}$ Department of Ecology and Evolutionary Biology, University of California, Santa Cruz, California 95064, USA \\ ${ }^{4}$ Research Department, Phillip Island Nature Parks, Cowes, Victoria 3922, Australia \\ ${ }^{5}$ Taronga Conservation Society Australia, Mosman, New South Wales 2088, Australia \\ ${ }^{6}$ Present address: Australian Antarctic Division, Department of Agriculture, Water and Environment, Kingston, \\ Tasmania 7050, Australia \\ ${ }^{7}$ Present address: Biodiversity Conservation Trust, Coffs Harbour, New South Wales 2450, Australia \\ ${ }^{8}$ Present address: San Francisco Bay Bird Observatory, 524 Valley Way, Milpitas, California 95035, USA \\ ${ }^{9}$ Present address: SARDI Aquatic Sciences, West Beach, South Australia 5024, Australia
}

\begin{abstract}
As large carnivores recover from over-exploitation, managers often lack evidencebased information on species habitat requirements and the efficacy of management practices, particularly where species repopulate areas from which they have long been extirpated. We investigated the movement and habitat use by 2 semi-aquatic carnivores (Australian fur seals ArCtocephalus pusillus doriferus and New Zealand fur seals A. forsteri) at the northern end of their distributions in Australia, where after a long absence both are recolonising their historic range. We also assessed male fur seal habitat use overlap with terrestrial and marine protected areas (PAs). While at the margin of the range during winter and early spring, the males remained inshore close to terrestrial sites and where interactions with humans often occur. From early spring, the males from the range margin showed uniform movement toward colonies in the core of the species' range prior to their breeding seasons. This contrasts with males tracked from the core of the species' range that returned periodically to colonies during the year, and highlights the importance of range-wide monitoring of a species to inform conservation planning. Habitat use by some males included over $90 \%$ of a marine PA at the margin of the species' range. Most terrestrial haul-outs used were within terrestrial PAs, while sites not protected were on the margin of the range. Despite wide-ranging habits, their dependence on coastal sites, where human access and activities can be regulated and more readily enforced, suggests that terrestrial and marine PAs will continue to play an important role in managing the recovery of these fur seals.
\end{abstract}

KEY WORDS: Fur seal - Arctocephalus - Habitat use - Distribution - Population recovery · Recolonisation $\cdot$ Human-wildlife interaction

\section{INTRODUCTION}

Conservation efforts have increased the population sizes of many large carnivores, and have either expanded their ranges or allowed recovery into histori-

*Corresponding author: marcussalton@gmail.com cal ranges (Chapron et al. 2014, Gompper et al. 2015, Karamanlidis et al. 2015, Martínez Cano et al. 2016). These changes often result in increased conflicts between humans and carnivores and among humans (e.g. conservationists and industries) (Treves \& Karanth

(C) The authors 2021. Open Access under Creative Commons by Attribution Licence. Use, distribution and reproduction are unrestricted. Authors and original publication must be credited. 
2003, Miller et al. 2013). Interactions at expanding range margins can be challenging for humans, who are more often ill prepared to manage such change (Ciucci \& Boitani 1998, Trouwborst et al. 2015, Morehouse \& Boyce 2017). While lethal methods are often deployed to alleviate conflict, they are counter-productive for conservation of recovering species and do not necessarily reduce conflicts (Stahl et al. 2001, Treves 2009). Non-lethal management alternatives (e.g. Shivik 2004) are important to resolve humancarnivore conflicts and create a future where humans and competing wildlife coexist (Woodroffe et al. 2005). Accordingly, there is growing interest in identifying habitat selection by large carnivores and locating potential 'conflict hotspots' (Miller 2015). This can help prioritise limited management resources into areas with high-risk human-carnivore interactions. In this study, we investigated the movements of individuals from recovering populations of large semi-aquatic carnivores, fur seals, which are often seen by fishermen as competitors. We focussed on a region where 2 species have recently greatly expanded their geographic ranges after a long absence resulting from sealing in the $19^{\text {th }}$ and early $20^{\text {th }}$ centuries. We quantified habitat use and compared marine and terrestrial areas in relation to their protected status for conservation planning.

Protected areas are a widely used, multi-purpose management tool (J. E. Watson et al. 2014). Protected areas may conserve biodiversity and ecosystem functions, protect natural and cultural features, preserve human assets (e.g. forests and water resources) and minimise human impacts. By regulating human access and activities, protected areas can play a role in mitigating negative interactions with wildlife and aid the recovery of large carnivores (Linnell et al. 2005, Chapron et al. 2014, Santini et al. 2016). Protected areas are used in terrestrial and marine contexts, and when located along a coastline, they can assist in managing human impacts on adjacent marine and terrestrial habitats (Stoms et al. 2005). These areas are typically not designed specifically to mitigate interactions between humans and wide-ranging species, because their small boundaries do not sufficiently capture the species' large foraging ranges (Hooker et al. 2011). However, despite many large carnivores ranging widely to feed, they often use discrete areas for essential activities such as breeding, moulting, resting and avoiding predators; for these activities, discrete protected areas may have beneficial effects (Huon et al. 2015, McAllister et al. 2015, Pérez-Jorge et al. 2015).

Protected area design often includes multiple use zoning where human activities are restricted to dif- ferent extents depending upon intent. For example, within Australia's marine park network, there may be 4 or more tiers of protection zones, ranging from no-take zones to areas where only certain types of fishing (e.g. commercial) are prohibited (Roberts et al. 2018). These zones can focus human activities into areas where they will cause the least disruption to animals, whilst allowing compatible activities to continue. With effective mitigation of negative humancarnivore interactions, protected areas can help sustain populations (Barnes et al. 2016), directly improve their demographic parameters (Gormley et al. 2012) and support ecosystem recovery (Prato et al. 2013). This suggests that conservation management of carnivores moving back into their historical ranges could be improved if existing protected areas with suitable habitat for essential activities by these carnivores could be identified.

Semi-aquatic species have a strong reliance on coastal habitats where we now also have high-density human populations, so it is not surprising that they have a long history of interactions with humans. Many species have been harvested, or culled to reduce fisheries and aquaculture interactions, but are now recovering (Gerber \& Hilborn 2001, Kirkwood \& Goldsworthy 2013, Magera et al. 2013). In Australia, the New Zealand fur seal Arctocephalus forsteri (also called long-nosed fur seal, Shaughnessy \& Goldsworthy 2015) and the Australian fur seal A. pusillus doriferus are both recovering from past exploitation (Shaughnessy et al. 2015, McIntosh et al. 2018b). Both species are protected by national law under the Environmental Protection and Biodiversity Conservation Act 1999 and are the subjects of a national strategy to minimise adverse interactions with human activities (National Seal Strategy Group 2007). As with other semi-aquatic species, interactions between fur seals and humans occur on land and at sea, with fisheries, aquaculture and tourism industries and the general public (Kirkwood et al. 2003, Shaughnessy et al. 2003, Robinson et al. 2008b), and are likely to increase as seal populations continue to recover and industries develop (Schumann et al. 2013). These interactions can result in economic loss or injury to humans, and stress, changed behaviour, injury or death of seals. Therefore, it is important to have accurate information to correctly assess seal-human interactions and their consequences as seal populations recover (Costalago et al. 2019).

Currently, little information is available on the movements and habitat use by the 2 fur seal species in Australasia on which to base management plans, as most information is focussed on females (Harcourt 
et al. 2001, Kirkwood \& Goldsworthy 2013, Hoskins et al. 2017). Most studies on male movements and habitat use are from the core of the species' range (Kirkwood et al. 2006, Page et al. 2006, Knox et al. 2017). These studies have focussed on foraging behaviour and at-sea habitat use: Australian fur seals occupy mostly shelf waters (Kernaléguen et al. 2015, Knox et al. 2017), and New Zealand fur seals occupy a combination of shelf and pelagic waters (Page et al. 2006). Their at-sea movements can be strongly associated with fishing activities, such as fish farms, which generate a predictable source of food (Robinson et al. 2008a). While there is some segregation in behaviour and foraging niche between these 2 fur seal species (Page et al. 2005, 2006, Hardy et al. 2017, Hoskins et al. 2017), both interact similarly with human activities and accordingly management practices tend not to differentiate between them. With studies focussed on the foraging behaviour and broader habitat use (e.g. benthic versus pelagic) of seals, there is limited information on how they use discrete terrestrial haul-out sites and the waters adjacent to those sites, where interactions with tourism and recreational activities often occur, and can have lethal consequences (Back et al. 2018). Importantly, movements and habitat use by male fur seals at the periphery of both species' geographic range are unknown: this is the case in New South Wales, along the east coast of Australia, where the population is growing and a breeding population recently established (Warneke 1975, Irvine et al. 1997, Hardy et al. 2017). This continuing expansion along the margin of their range is therefore likely to see an increase in human-wildlife conflict, and humans appear to be less experienced and prepared for this type of conflict (Shaughnessy et al. 2008).

The east coast of Australia is subject to significant coastal development and human use of marine resources. Networks of marine protected areas have been established to protect representative marine habitats and biological diversity, and to maintain ecosystem processes (Lynch et al. 2013), but have not been designated specifically to protect seals. As fur seals have expanded northward along the east coast, they have established haul-outs within one of these marine protected areas: Jervis Bay Marine Park (JBMP). The seals are now seasonally abundant in JBMP (Burleigh et al. 2008), but it is unclear what habitats they require and whether these habitats are within existing marine and terrestrial protected areas.

We investigated the on-land and at-sea movements and habitat use by 2 species of fur seals that reside in the expanding margin of their range. By evaluating the frequency of visitation to different habitats, we identified areas likely to be important to the seals and where interactions with humans could be most acute. By overlaying haul-out site use and foraging ranges with the distribution of terrestrial and marine protected areas, we assessed whether important areas used by seals at the margin of their range are receiving protection. The seals at this range margin are seasonally abundant, so the tracking study also aimed to determine how long the seals are in residence and where they go when they leave. This may help conservation managers to identify habitats into which the population might expand; thus, connectivity between core and peripheral populations was also investigated.

\section{MATERIALS AND METHODS}

\subsection{Animal handling and data collection}

The movements of male New Zealand fur seals (NZFS) and Australian fur seals (AuFS) from Lamond Head, Jervis Bay, Australia (353' S, $\left.150^{\circ} 50^{\prime} \mathrm{E}\right)$ (Fig. 1) were recorded with Mk10-AFs Fastloc-GPS devices (Wildlife Computers; $105 \times 60 \times 20 \mathrm{~mm}$, $240 \mathrm{~g}$ ). Individuals were selected based on their proximity to a suitable access point to their rocky platform terraces at the base of a $30 \mathrm{~m}$ high cliff face. Species were distinguished by their pelage, facial structure and cusps on their post-canine teeth (Kirkwood \& Goldsworthy 2013). To attach the device, each seal was sedated with a light intra-muscular injection of zoletil (dose rate based on estimated seal weight was 1 to $1.5 \mathrm{mg} \mathrm{kg}^{-1}$ ) that was delivered remotely with the aid of a pneumatic dart-gun, then approached and restrained in a catch net before being maintained under sedation with a mix of oxygen and isoflurane (approximately 1.5 to $2 \%$ isoflurane; adjusted as required) delivered via a portable vaporiser (Gales \& Mattlin 1998). While sedated, seals were measured using standard methods (Kirkwood et al. 2006), and the telemetry device was glued to the dorsal midline of each seal with a quick-setting epoxy (Araldite ${ }^{\circledR}$ K-268, Huntsman Advanced Materials; Quick Set Epoxy Resin 850-940, RS Components). Measurements were used to approximate the life stage of individuals (juvenile or adult) (Warneke \& Shaughnessy 1985, Arnould \& Warneke 2002, McKenzie et al. 2007a,b). Deployments occurred in 2011, 2012 and 2013 from June to August, when seal numbers ashore tend to increase (Burleigh et al. 2008). The devices transmitted GPS location (collected at 2 min intervals, 


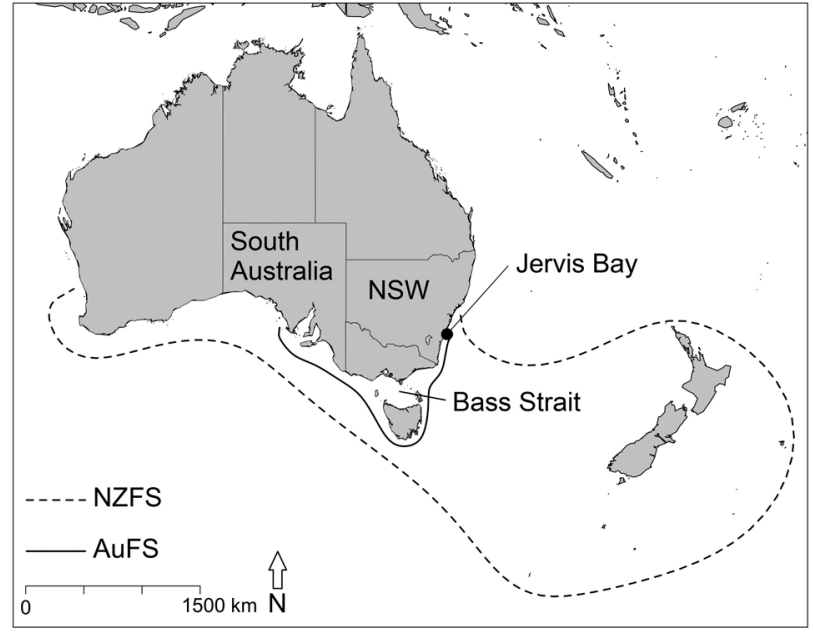

Fig. 1. Approximate range of New Zealand fur seals (NZFS) Arctocephalus forsteri and Australian fur seals (AuFS) A. pusillus doriferus (dashed line and solid line, respectively) and the site of deployment (Lamond Head, Jervis Bay; solid circle) in New South Wales, Australia (NSW Marine Parks Authority 2010). NSW is at the margin of both species' range (i.e. the edge of their breeding range and where several haul-out sites are established), and Bass Strait and the South Australia coast are the core of the range (where large breeding popula-

tions occur) for AuFS and NZFS species, respectively

and median fix rate received via satellite transmission was 1 fix per $1.5 \mathrm{~h}$ ), behaviour data (e.g. dive and surface interval events, including their duration) and histogram summary data (e.g. percentage time at different depths and performing dives in $6 \mathrm{~h}$ intervals) via the Argos satellite network (Collecte Localisation Satellites) until the battery failed or the tag fell off the seal. Fastloc-GPS locations were post-processed with satellite ephemeris and almanac data (Fastloc-GPS Solver version 1.0.56, Wildlife Computers), which retained locations with at least 4 satellite acquisitions and an accuracy typically within 10s of metres (Dujon et al. 2014).

\subsection{Movements on land and at sea}

To distinguish when a seal was at sea (i.e. on a 'trip') or on land (i.e. hauled out), we used a combination of data sources from the telemetry device to complete gaps in individual data sources. First, locations were pre-defined as wet or dry by the device, based on the conductivity sensor. Second, between location time-stamps, we used behaviour data on single dives (movements below $2 \mathrm{~m}$ for greater than 10 s), post-dive surface intervals (i.e. an interval when the tag was at the surface and wet) and surface intervals ashore (i.e. an interval when the tag was at the surface and dry for 20 consecutive minutes and ceased when wet for $>30 \mathrm{~s}$ of a minute). Third, between location time-stamps and in the absence of behaviour data, we used histogram data summaries of time spent in dive and surface behaviours and periods hauled-out. A seal was indicative of being at sea between time-steps where the device was recorded as wet, dives or post-dive surface intervals were recorded, and $100 \%$ of a $6 \mathrm{~h}$ histogram summary was spent in dive and surface behaviours. A seal was indicative of being on land when the device was recorded as dry and where $100 \%$ of a $6 \mathrm{~h}$ histogram summary was spent hauled out. To better estimate the time on land and at sea, the transition between land and water was estimated to occur at the mid-point between an interval on land and at sea. If no location was recorded while a seal was defined as being on land, a haul-out location (or 'site') was assigned based on the proximity of recent locations to known haul-out sites.

On-land locations were pre-processed to account for variance in location accuracy when quantifying terrestrial habitat use. Locations were visually clustered into groups or 'sites', based on known site locations and applying a maximum 200 m diameter per group (which was the size of most point clusters and consistent with the size of known haul-out sites, (M. Salton pers. obs.). We then calculated the length of time on land, or 'visits' ashore, the frequency of visits to each site and the number of individuals visiting each site. Sites were defined as being either a non-breeding site or breeding site based on a recent pup census throughout the species' range (McIntosh et al. 2014) and knowledge from experienced observers (R. Kirkwood pers. obs. and A. Irvine pers. comm.).

At-sea habitat use was quantified using 2 parameters: trip duration and foraging range. Trip duration was the time elapsed between a departure and a return to land. The foraging range was quantified using permissible home range estimation (Tarjan \& Tinker 2016). This method incorporates underlying environmental information into probability estimates to define a permissible foraging range. Land was used as the environmental predictor (i.e. proximity to coast/ land). Distance-from-land values were measured as the Euclidean distance from the closest shoreline feature (GEODATA Coast 100K 2004, Geoscience Australia). Areas on land were assigned a distance value of 0 . The distance-from-land values were log-transformed to normalize the empirical data distribution. The smoothing parameter was calculated using the 
univariate plug-in selector of Wand \& Jones (1994) for the distance-from-land values, employed in the $\mathrm{R}$ package 'ks' v1.8.13 (Duong 2013). Probability values were estimated across 2 scales depending on location as a compromise between resolution and processing time: (1) a $500 \times 500 \mathrm{~m}$ grid for areas $<40 \mathrm{~km}$ from shore, and (2) a $5000 \times 5000 \mathrm{~m}$ grid for areas $>40 \mathrm{~km}$ from shore. The at-sea distribution for each individual was quantified at the margin of the range (i.e. New South Wales, at the edge of the breeding range and where several haul-out sites are established) and core of the range (where numerous breeding sites are located) using the $90 \%$ utilisation distribution (home range; HR) and 50\% utilisation distribution (core range; $\mathrm{CR}$ ). To test change in foraging trips and the size of the distributions between the margin and core of their range, we used a Student's $t$-test and a Wilcoxon's test, respectively, with the latter based on paired individuals (i.e. those for which we recorded distributions in both parts of the range) and accounted for non-normal distributions and unequal variance. The variability among individuals was assessed by calculating the total area used by all individuals and the percentage of that area used by 2 or more individuals (e.g. the area where at least 2 distributions overlapped).

\subsection{Overlap with protected areas}

We used different approaches to assess whether terrestrial and at-sea habitat used by the seals overlapped with protected areas, because haul-out sites were discrete locations while at-sea areas were spatial areas (i.e. polygons). Haul-out sites were classed as inside or outside a protected area, where a protected area is any spatial management area listed under the IUCN global protected area programme (Dudley 2008). The primary interest was at the margin of the range, but we also assessed how seals used sites and the overlap of sites with terrestrial protected areas when the seals dispersed from the margin of the range. For at-sea habitat use, we quantified how much of a fur seal's foraging range overlapped with the marine protected area that was consistently occupied by the seals at the margin of the range, i.e. JBMP. All data were processed and analysed with R v2.15.1 (R Development Core Team 2012). Means are presented $\pm \mathrm{SE}$.

\section{RESULTS}

Eleven adult male NZFS were tagged (4 in 2011, 2 in 2012, 5 in 2013) and 4 adult male AuFS were tagged in 2013. NZFS weighed $95 \pm 6 \mathrm{~kg}$ and AuFS weighed $160 \pm 39 \mathrm{~kg}$ (Table 1). The 15 seals were tracked for $129 \pm 51$ d (range: 21-204 d), and the period of tracking covered 21 June to 25 January in 2011, 2012 and 2013 (Table 1). We recorded 865 trips (range: 17-91 trips per seal), and from these we calculated that individuals spent $70 \pm 7 \%$ of their time at sea (range: 58-82\%) (Table 1) and otherwise they were on land.

\subsection{Behaviour at the margin of the range}

All seals remained at the northern margin of the range (i.e. New South Wales, Australia) during the austral winter months. From 17 September, both species departed the margin of the range and moved south towards the core of the range where there are established breeding colonies (mean departure dates: AuFS 13 October \pm 10 d, NZFS 15 October $\pm 6 \mathrm{~d}$ ).

The seals used 26 haul-out sites while at the margin of the range and spent $14.8 \pm 1.0 \mathrm{~h}$ ashore (range: $25 \mathrm{~min}$ to $4.2 \mathrm{~d}$ ). Each individual visited between 4

Table 1. Deployment summary for male New Zealand fur seals (NZ) Arctocephalus forsteri and Australian fur seals (Au) A. pusillus doriferus at Lamond Head, Jervis Bay, New South Wales (Australia) in austral winters of 2011 to 2013. Dates are given as d/mo/yr

\begin{tabular}{|lcccccr|}
\hline $\begin{array}{l}\text { Seal } \\
\text { ID }\end{array}$ & $\begin{array}{c}\text { Length } \\
(\mathrm{m})\end{array}$ & $\begin{array}{c}\text { Girth } \\
(\mathrm{m})\end{array}$ & $\begin{array}{c}\text { Date } \\
\text { attached }\end{array}$ & $\begin{array}{c}\text { Deployment } \\
\text { duration }(\mathrm{d})\end{array}$ & $\begin{array}{c}\text { Time at } \\
\text { sea }(\%)\end{array}$ & $\begin{array}{c}\text { GPS } \\
\text { locations }\end{array}$ \\
\hline NZ_1 & 1.56 & 1.05 & $21 / 06 / 11$ & 194.5 & 74.3 & 1341 \\
NZ_2 & 1.75 & 0.98 & $25 / 06 / 11$ & 21.2 & 58.5 & 168 \\
NZ_3 & 1.59 & 1.06 & $05 / 07 / 11$ & 86.9 & 61.5 & 483 \\
NZ_4 & 1.58 & 1.09 & $09 / 07 / 11$ & 55.4 & 72.5 & 339 \\
NZ_5 & 1.64 & 1.05 & $01 / 07 / 12$ & 159.2 & 68.7 & 266 \\
NZ_6 & 1.61 & 0.99 & $30 / 06 / 12$ & 112.0 & 62.6 & 339 \\
NZ_7 & 1.51 & 0.93 & $22 / 06 / 13$ & 158.2 & 72.8 & 593 \\
NZ_8 & 1.65 & 1.01 & $10 / 07 / 13$ & 166.0 & 82.5 & 639 \\
NZ_9 & 1.7 & 1.11 & $11 / 07 / 13$ & 104.7 & 77.5 & 385 \\
NZ_10 & 1.59 & 1.12 & $27 / 07 / 13$ & 102.3 & 65.6 & 189 \\
NZ_11 & 1.58 & 1.06 & $10 / 08 / 13$ & 135.3 & 64.9 & 416 \\
Au_1 & 1.49 & 0.99 & $19 / 06 / 13$ & 204.3 & 73.1 & 441 \\
Au_2 & 1.85 & - & $20 / 06 / 13$ & 153.4 & 66.8 & 898 \\
Au_3 & 1.42 & 0.9 & $11 / 07 / 13$ & 112.5 & 75.4 & 481 \\
Au_4 & 2.06 & 1.63 & $31 / 07 / 13$ & 178.1 & 66.9 & 1204 \\
\hline
\end{tabular}


and 10 sites $(6.2 \pm 1.9$ sites $)$. Most sites were nonbreeding sites, with records of pups only on Montague Island (Fig. 2). The deployment site was revisited by 13 of 15 individuals (post-deployment): several sites were visited by 5 to 7 individuals (Fig. 2). Most sites were used by both species ( $\mathrm{n}=16$ sites), with 9 visited by NZFS only and 1 by AuFS only. Generally, sites were visited infrequently, with some only visited once ( 5 sites) or fewer than 10 times (11 sites). The deployment site (Lamond Head) was the most frequented (a non-breeding site, 391 visits, or $59.3 \%$ of all visits to sites at the margin of the range). This may be indicative of high site fidelity or favourable site conditions (note that males tracked from Montague Island in 2012 and 2013 often visited this site when they came ashore in this area, R. Harcourt \& D. Slip unpubl. data). The next most frequented sites had 38, 36 and 32 visits and were 145,



Fig. 2. (a-c) Sites visited by male fur seals and their overlap with a terrestrial protected area (PA); overlap (circle) or no overlap (triangle). Symbol size indicates the frequency of visits to a site and colour indicates non-breeding haul-out site (orange) or a colony (pink) (rare breeding attempts at Montague Island). The dashed line in (a) indicates the $200 \mathrm{~m}$ bathymetric contour and approximate edge of the continental shelf. (b) Enlargement of the marked area (rectangle) in (a). Diagonal hashed areas (green) indicate a terrestrial PA (southern Jervis Bay) and a naval exclusion zone (north Jervis Bay). (c) Enlargement of the marked area (square) in (b). Horizontal area (blue) in (b) and (c) is Jervis Bay Marine Park
18 and $65 \mathrm{~km}$ away from the deployment site, respectively (Fig. 2).

While at the margin of the range, NZFS trips at sea were either on the continental shelf or in pelagic waters east of the shelf, and AuFS foraging trips were concentrated on the shelf (Fig. 3). Seals moved up to $250 \mathrm{~km}$ north of Jervis Bay to the coastline off the highly populated city of Sydney. The size of individual HR area at the margin of the range was $2467 \pm$ $843 \mathrm{~km}^{2}$, and was similar in size for both species (Table 2). The individual HR and CR areas overlapped, and the area of high overlap for CR areas was predominantly in the coastal waters within $20 \mathrm{~km}$ of the frequently used haul-out sites (Fig. 3). While at the margin of the range, at-sea trip durations were $1.7 \pm 0.2 \mathrm{~d}$ (range: $38 \mathrm{~min}$ to $35.1 \mathrm{~d}$ ) for individuals of both species, and approximately onefifth of their at-sea trips were $<0.5 \mathrm{~d}$ in duration (Table 2), during which time individuals remained within inshore waters adjacent to terrestrial sites (average individual mean maximum distance of $8 \pm 6 \mathrm{~km}$ from site of departure).

\subsection{Behaviour at the core of the range}

After seals departed the margin of the range, 10 tags continued to transmit data (6 NZFS and 4 AuFS). During this period, the seals used 31 haul-out sites and spent $22.2 \pm 2.6 \mathrm{~h}$ ashore (range: $25 \mathrm{~min}$ to $3.9 \mathrm{~d}$ ). The sites used by the seals were spread across multiple jurisdictional boundaries, comprising 3 Australian states (Victoria, Tasmania and South Australia) and New Zealand (Fig. 3). Most sites were non-breeding sites, with only 10 of the 31 sites known for breeding activity. Individuals visited between 1 and 10 different sites throughout the core of their range. Eight of the 10 seals visited at least 1 breeding site, where they spent $21.5 \pm$ $3.4 \mathrm{~h}$ ashore (range: $25 \mathrm{~min}$ to $3.9 \mathrm{~d}$ ). Most sites were visited by only 1 individual (20 sites), but some sites were visited by up to 3 individuals (6 sites). Seven sites were visited by both species, 12 sites only by NZFS and 12 sites only by AuFS. Most sites were visited infrequently, either once (8 

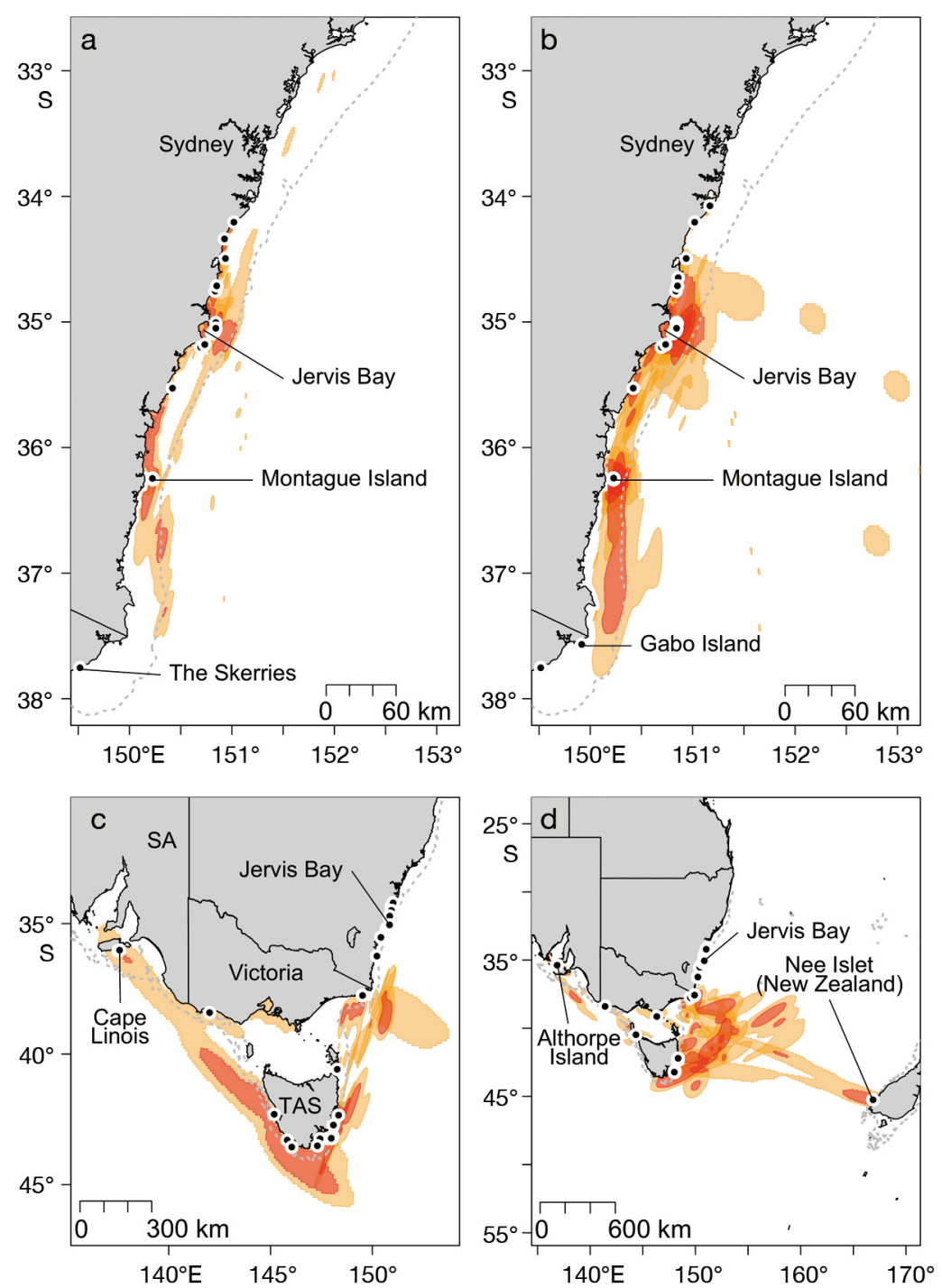

Fig. 3. Home range (orange) and core range (red) utilisation distributions of each individual male fur seal tracked from Jervis Bay in 2011 to 2013. (a) Australian fur seals Arctocephalus pusillus doriferus at the margin of the range $(n=4)$ and (c) core of the range $(n=4) ;(b)$ New Zealand fur seals $A$. forsteri at the margin of the range $(n=11)$ and $(d)$ core of the range $(n=8)$. At the time of tracking, The Skerries was the north-eastern extent of the breeding sites for these fur seals (i.e. core geographic range), with rare breeding attempts at Montague Island. Darker shades indicate greater overlap among individuals. Dashed lines are the $200 \mathrm{~m}$ bathymetric contour and approximate edge of the continental shelf. SA: South Australia, TAS: Tasmania

sites) or fewer than 10 times (26 sites). The most frequently used site was The Skerries (breeding site, 79 visits, or $34.5 \%$ of all visits to sites at the core of the range). The next most frequently used sites were Althorpe Island (non-breeding site, 23 visits, or 10.0\%), Gabo Island (non-breeding site, 18 visits, or $7.9 \%$ ) and Cape Linois (non-breeding site, 15 visits, or 6.6\%).

While at the core of the range, NZFS trips to sea were primarily in pelagic waters east of the continen- tal shelf between Australia and New Zealand, and AuFS trips remained on the continental shelf but also around the shelf break, with 1 individual venturing off the shelf. The fur seals displayed a change in foraging behaviour from the margin of the range to the core of the range; while their foraging trip duration was not significantly different (Student's paired $t$-test, $t=-2.23, \mathrm{p}=0.052$ ), they had significant expansion of their HR (Wilcoxon signed-rank test, $V=0, Z=-3.3$, $\mathrm{p}<0.001, \mathrm{R}=0.99$ ) (Fig. 3, Table 2). There was high variability among individual $\mathrm{HR}$ and $\mathrm{CR}$, and only a small percentage of the total area was used by 2 or more individuals (HR: $29.5 \%$ and CR: $11.0 \%$ ).

During October, 1 NZFS (NZ_13) traversed the Tasman Sea. The seal left Montague Island (on 2 October) and reached Nee Islets, New Zealand, on 10 November. This seal spent $15 \mathrm{~d}$ around the Nee Islets and a total of $9.5 \mathrm{~d}$ hauled out there. The seal left the Nee Islets on 24 November, traversed the Tasman Sea and hauled out at Cape Hauy, Tasmania, on 18 December for $1.2 \mathrm{~d}$.

\subsection{Protected areas}

Of the 57 sites used by the seals, most $(\mathrm{n}=47$ ) were within terrestrial protected areas (i.e. national parks, reserves, naval exclusion area) (Fig. 2). All 10 sites that were outside terrestrial protected areas were non-breeding haul-out sites at the margin of the range (Fig. 2). Six of the sites outside terrestrial protected areas were along the Jervis Bay coastline and the other 4 were north of Jervis Bay towards Sydney. There was no difference in the average number of visits to sites outside terrestrial protected areas $(7.5 \pm 7.6$ visits) compared to sites inside terrestrial protected areas $(7.3 \pm 8.5$ visits, excluding the deployment site, which was an extreme outlier). A total of 591 visits were recorded at 13 sites in JBMP (range: 1-391 visits per site). After the deployment site, the frequency of use of other sites in Jervis Bay was relatively low 
Table 2. Foraging behaviour parameters (mean $\pm \mathrm{SE}$ ) of male New Zealand fur seals (NZFS) Arctocephalus forsteri and Australian fur seals (AuFS) A.pusillus doriferus when they were at the margin of the range (i.e. New South Wales) and in the core of their range. Parameters include home range ( $\mathrm{HR}_{;}$90\% utilisation distribution) and core range size (CR; $50 \%$ utilisation distribution). For seals at the margin of the range, we also investigated how much of Jervis Bay Marine Park (JBMP) was used, and the overlap of individual HR and CR with JBMP

\begin{tabular}{|lcc|}
\hline Region and parameter & NZFS & AuFS \\
\hline Margin of the range & & \\
Number of seals & 11 & 4 \\
Haul-out duration (h) & $14.2 \pm 1.3$ & $16.4 \pm 1.5$ \\
Trip duration (d) & $1.4 \pm 0.2$ & $1.8 \pm 0.4$ \\
HR size $\left(\mathrm{km}^{2}\right)$ & $2612 \pm 1133$ & $2068 \pm 778$ \\
CR size $\left(\mathrm{km}^{2}\right)$ & $587 \pm 266$ & $427 \pm 208$ \\
Trips $<0.5$ d $(\%$ of individual's & $23.9 \pm 5.6$ & $19.9 \pm 2.9$ \\
$\quad$ total no. trips) & $28.1 \pm 7.2$ & $41.4 \pm 19.6$ \\
JBMP area used (\%) & $10.1 \pm 3.7$ & $9.9 \pm 5.3$ \\
HR overlap with JBMP (\%) & $12.5 \pm 8.2$ & $16.4 \pm 15.8$ \\
CR overlap with JBMP (\%) & & \\
Core of the range & 6 & 4 \\
Number of seals & $18.9 \pm 2.3$ & $28.7 \pm 5.3$ \\
Haul-out duration (h) & $3.4 \pm 0.9$ & $4.1 \pm 1.5$ \\
Trip duration $(\mathrm{d})$ & $153140 \pm 40517$ & $88394 \pm 57877$ \\
HR size $\left(\mathrm{km}^{2}\right)$ & $33972 \pm 8607$ & $22039 \pm 14816$ \\
CR size $\left(\mathrm{km}^{2}\right)$ & $43.1 \pm 8.4$ & $28.3 \pm 16.4$ \\
Trips $<0.5$ d $(\%$ of individual's & & \\
total no. trips) & & \\
\hline
\end{tabular}

that of males that reside at the core of the species' range, but they used much larger ranges and had consistent seasonal movements away from the margin to the core of their distribution. Despite being wide-ranging predators, the males consistently used discrete terrestrial sites and adjacent inshore waters while at the margin of the range, and these habitats were either coincidentally, or actively, selected for reduced disturbance, falling within established terrestrial and marine protected areas.

Many large marine carnivores, such as seals, crocodiles, turtles and seabirds, range widely at sea, but return periodically to land to rest, breed and moult, and this can bring them into close contact with coastal human populations. Consistent use of particular discrete inshore habitats makes terrestrial and marine protected areas a viable management option for mitigating human-carnivore conflict, at least where the 2 areas coincide. Protected areas are often designed with human and ecosystem values in mind (Thackway \& Cresswell 1997), and not specifand did not appear to be influenced by whether the site was inside or outside a protected area (Fig. 2).

While at the margin of the range, individuals of both species used a large percentage of JBMP (up to $93 \%$ of the park; Table 2, Fig. 4). As expected for a wide-ranging species, only a percentage of an individual's HR overlapped with JBMP; however, there was great individual variability with the CR of some individuals being almost entirely within JBMP (up to $92 \%$ of an individual's CR overlapped within the park; Table 2). When the home range or core range of a seal overlapped with JBMP, the overlap occurred mostly within the coastal waters adjacent to haul-out sites (Fig. 4).

\section{DISCUSSION}

We tracked the movements and habitat use of sympatric male AuFS and NZFS at the northern end of their distribution where both species are expanding their range, to identify areas important to these predators and determine if they are receiving protection there. Habitat use by the study males was similar to ically for wide-ranging carnivores, and yet in this study they appear to capture most of the terrestrial habitat used by the seals. The seals received protection throughout much of their range as a result of management of activities in protected areas, with the exception of some sites at the expanding northern margin of their range. Wide-ranging marine carnivores may opt to use protected areas specifically because of functions offered within their boundaries (e.g. less human activity or different activities, such as prohibited rock fishing). Alternatively, the areas humans zoned for protection have features that are coincidently also favoured by the carnivores (e.g. remote areas, low human visitation, limited commercial activity). When marine carnivores are on land they can be disturbed by visual, aural and olfactory cues whether approached from land or sea $(\mathrm{H}$. Watson et al. 2014, Cowling et al. 2015, Marcella et al. 2017) or from the air by piloted and remotely operated aircraft (Born et al. 1999, Bevan et al. 2018, McIntosh et al. 2018a), which at worst may have lethal consequence (Back et al. 2018). An effective way to reduce disturbance to marine carnivores on land is to restrict access and modify behaviour of humans, for example 

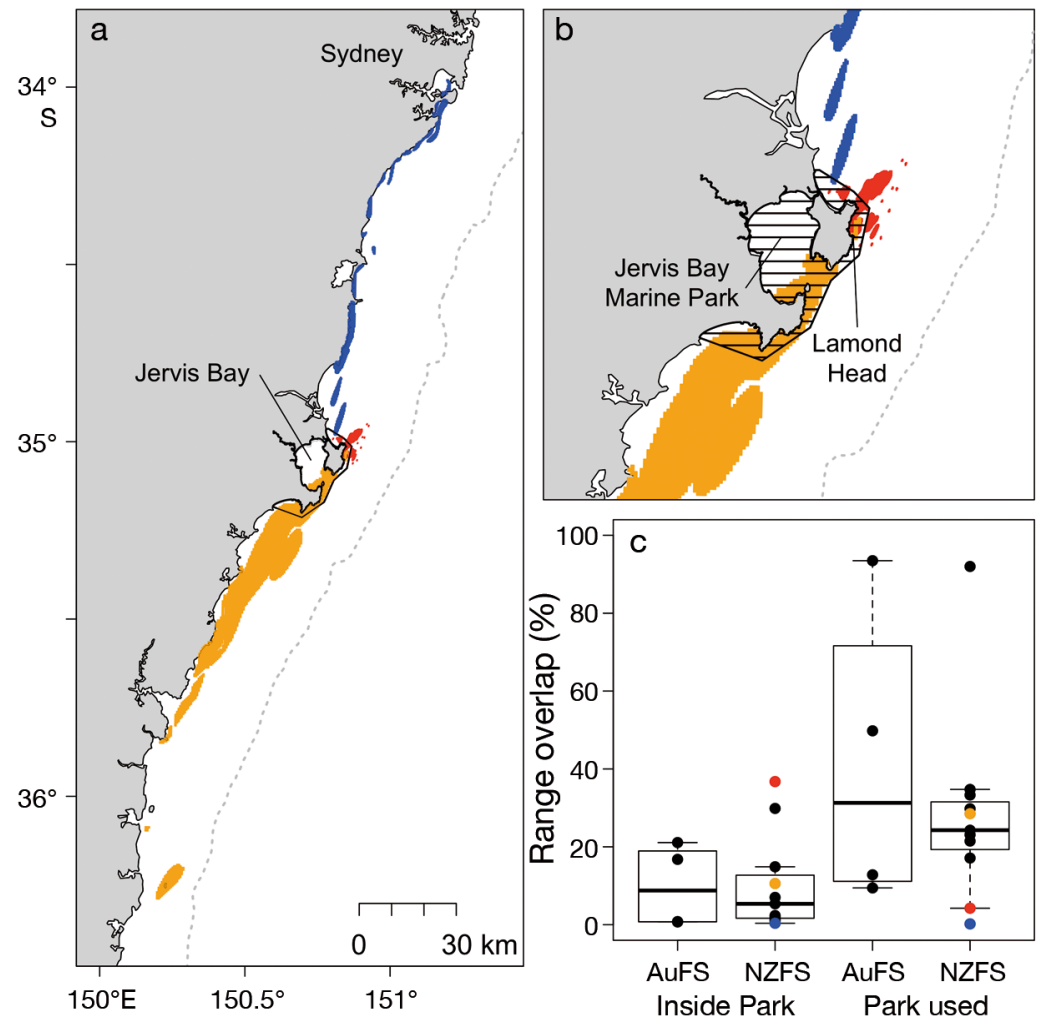

Fig. 4. Overlap of individual male Australian (AuFS) and New Zealand (NZFS) fur seal home ranges with Jervis Bay Marine Park. $(a, b)$ Home ranges of 3 individuals are presented with different colours (red, orange, blue), and the same colours used to represent these individuals in the box plots in panel c. Dashed line is the $200 \mathrm{~m}$ bathymetric contour and approximate edge of the continental shelf. (c) Percentage of the range contained within the park (Inside park) and the percentage of the park utilised by each seal (Park used) (dot per individual). Minimum and maximum are delimited by the whiskers, the box represents the 25 th to 75 th percentile, and thick line represents the median. Dots represent each individual's value

by installing barriers and/or interpretive signage (Cassini et al. 2004, Granquist \& Sigurjonsdottir 2014, Marschall et al. 2017) and regulating approach distances for different aircraft types with minimum height restrictions (Hodgson \& Koh 2016). Protected areas allow strict regulation of human access and activities and have proven applicable for conserving large carnivores through reduced negative interaction with humans (Hooker \& Gerber 2004, Barnes et al. 2016, Santini et al. 2016). Minimising human disturbance to provide refugia may be particularly important for low-density populations, such as those at the margin of a range where individuals may feel more at risk due to decreased vigilance and dilution effects (Stevens \& Boness 2003). A network of established protected areas along the coastal fringe may enhance recovery and range expansion of wideranging carnivores, like these seals, by providing important stepping stones of refuge as they expand their range (Kirkman 2010, Huisamen et al. 2011).

With tracking studies of wide-ranging marine carnivore focussing on foraging trips at sea, there has been less focus on what these carnivores are doing during short trips within inshore habitat. In this study, the considerable time spent on land and within inshore waters adjacent to terrestrial sites by all individuals of both species is indicative of the importance of this habitat to these marine carnivores at the margin of their range. Terrestrial sites are important to male fur seals for a variety of reasons (to breed, moult, rest, digest and seek refuge from marine predators), although at the margin of the range the benefit is unlikely associated with reproduction because there are no reproductively active females in the area. During the nonbreeding period, social interactions between males are likely to play an important role in gaining experience that determines hierarchy and breeding success (Stirling 1970, Miller 1974, McCann 1980). Little is known about the importance of inshore waters adjacent to terrestrial sites. Male NZFS and AuFS move between land and inshore waters to thermoregulate (Mattlin 1978, Garlepp et al. 2014), which may be more important for seals in warmer climates at lower latitudes (Stevens \& Boness 2003). The inshore environment may also provide valuable foraging grounds, with the diet of both fur seal species at Jervis Bay having a high prevalence of benthic, demersal and reef-associated prey associated with inshore habitats (Hardy et al. 2017). Inshore habitats may also be selected for features (e.g. shallow reefs and kelp beds) that improve evasion from predators (Wirsing et al. 2007, Wcisel et al. 2015). Supporting these critical functions with protection of terrestrial sites and inshore waters will facilitate recolonisation of these habitats throughout their historic range. The coastal margin of the range of these seals, the focus of this study, supports a large and dense human population, with active fishing, aquaculture and tourism industries. Mitigating atsea interactions with fur seals in the relatively discrete area found adjacent to terrestrial haul-out sites 
would be challenging at this margin of their range, but would likely benefit the recovery of the seals by reducing disruption to critical on-land and inshore behaviours.

Protecting the entire foraging range of wide-ranging marine carnivores is often impractical. By understanding the movements of carnivores, it is possible to identify life stages or periods within a breeding cycle that are contained in discrete areas more suitable for protected area zoning. For example, this study showed that when male seals were at the expanding margin of their range they used relatively small at-sea areas, with a large percentage overlap with the existing marine protected area, JBMP, and the park captured the core range areas that were adjacent to terrestrial sites. Through spatial zoning within their boundaries, marine protected areas can be used to direct marine-based activities (fishing, aquaculture, tourism) and land-based fishing and tourism activities into areas away from sites important to species of conservation concern. JBMP is an example of a park that is internally zoned to spatially regulate activities throughout the park, and since its establishment, several predators have returned and established populations in the park (Lynch et al. 2013, Bruce et al. 2014, this study). By identifying the areas within the park that are important to each marine carnivore, management authorities can apply evidence-based information to improve zoning within the park (i.e. modify boundaries or activities within zones) to better mitigate interactions between users and the carnivores. In the absence of such information, our study suggests that zoning the coastal marine environment close to terrestrial sites could capture important inshore habitat for wide-ranging marine carnivores that regularly come ashore, and provide the opportunity to mitigate interactions between these carnivores and human activities which disrupt behaviours that occur in terrestrial and inshore habitats.

Factoring novel and consistent intraspecific variation in foraging behaviour into movement models for carnivores is an important consideration to accurately predict the habitat use by populations of interest, and is necessary to correctly inform conservation planning. In this study, the uniform movement of the male AuFS and NZFS from overwintering at the margin of the range towards colonies prior to breeding contrasts with males tracked within the core of the range in other studies. Long-range movements from the winter grounds have occurred in only a small number of individuals tracked from the core of the range in other studies (NZFS: Page et al. 2006; AuFS:
Kirkwood et al. 2006, Robinson et al. 2008a, Knox et al. 2017). This sort of intraspecific variation in movements is rarely seen in other otariids, with males either all migrating away from colonies postbreeding (Robertson et al. 2006, Staniland \& Robinson 2008) or all showing high fidelity to a colony throughout the non-breeding period (Lowther et al. 2013, Baylis et al. 2018). This appears analogous to partial migrating species, where segregation in overwinter movement behaviour may be associated with individual characteristics such as age, body size, competitive ability and personality (Lundberg 1988, Chapman et al. 2011). Breeding status may explain the more consistent movement and colony fidelity of males tracked from the core of the range (Kirkwood et al. 2006), with those less involved in breeding in the subsequent season (e.g. holding or challenging for breeding territory) ranging more widely over winter. This idea is supported by our study, with all males on the margin of the range having minimal association with colonies in the subsequent breeding season and insufficient body size to be competitive for breeding territory (Lourie et al. 2014), although other strategies exist (Caudron et al. 2009). High intra- and inter-specific competition and local depletion of food resources at the core of a species' range, close to breeding areas, may be a strong motivation for some individuals to disperse from breeding colonies (Ashmole 1963, Boyd et al. 1998, Kuhn et al. 2014). As a trade-off, however, lower densities of peripheral populations are thought to reflect poorer quality habitat towards the margins of a range (Holt 1987, Lawton 1993, Guo et al. 2005), which is thought to explain divergent foraging behaviour from individuals at the core of the range (Augé et al. 2011). The movements of individuals at the periphery of a population's range can clearly diverge from the patterns identified in individuals at the core of their range. This study emphasises that caution is required when modelling habitat use of carnivores recolonising their historic range when using information derived from individuals at the core of their species' range.

This study identifies important considerations to improve conservation and management of recovering wide-ranging marine carnivore populations, based on analyses of movements and habitat use by males of 2 fur seal species occupying an expanding margin of their range. The dependence of many marine carnivore species on discrete habitats that are of similar size to existing protected areas means that recovering populations of marine carnivores can benefit from an established network of protected 
areas, both terrestrial and marine, at the frontier of their range. Improvements can be made to the designation and zoning of protected areas by integrating specific habitat use information of individuals at expanding range margins into the review of management plans. This will help account for unique intraspecific behaviour of individuals at range peripheries. As marine carnivores recolonise their historic ranges, it is necessary to consider ecosystem consequences, and the utility of protected areas, where high-level predators become established and exert influence on trophic dynamics within protected areas (Hooker et al. 2011, Kelaher et al. 2015). Having a network of protected areas along the coastal fringe at the margins of a carnivore's range could help to minimise and mitigate adverse interactions between industry and recovering marine carnivores, and thereby support key conservation and management objectives for marine carnivore populations. For these protected areas, it is important to ensure enforcement of regulations, as activities can persist illegally and reduce the effectiveness of the protected area (Harasti et al. 2019). Given that wide-ranging marine carnivores will often move beyond discrete habitats, point-source management methods, such as seal exclusion devices on trawl nets (Shaughnessy et al. 2003), will likely continue to play a role in mitigating at-sea interactions between humans and recovering marine carnivore populations.

Despite promising recovery of populations for both fur seal species throughout their range (Kirkwood et al. 2010, Shaughnessy et al. 2015, Watson et al. 2015), recent population estimates based on pup numbers identified a reduction in the AuFS population at core breeding colonies (McIntosh et al. 2018b). The implications of population fluctuations within the core of a species' range for the colonisation of the margin by peripheral populations is still unknown. In this case, resource partitioning, on land and at sea, between 2 recovering, sympatric predators requires further investigation, and studying this at the expanding margin of both species' range, where neither species currently has apparent priority, may provide useful insights for carnivore population recovery and recolonisation (Hardy et al. 2017). Importantly, the implications for large-scale environmental change, such as strengthening of the East Australian Current (Suthers et al. 2011), on the recovery of large carnivore populations and changes in their distribution are still largely unknown, but potentially significant (Niella et al. 2020), and should be considered when planning for recovery and expansion of marine carnivore populations.
Acknowledgements. We are grateful to the Australian Navy for logistical support with accessing the deployment site. We thank the New South Wales National Parks and Wildlife Service, Jervis Bay Marine Park and the Beecroft Ranger Station staff for their assistance with fieldwork. The research was financially supported by the Australian Marine Mammal Centre. The funders had no role in study design, data collection and analysis, decision to publish, or preparation of the manuscript. All procedures were conducted under Office of Environment and Heritage Animal Ethics Committee Approval (100322/03) and Macquarie University Ethics Committee Approval 2011/054. Research Permits (SL 100111 and SL 100746) and all relevant institutional and national guidelines for the care and use of animals were followed. We appreciate the efforts of 3 anonymous reviewers who commented on the manuscript.

\section{LITERATURE CITED}

Arnould J, Warneke R (2002) Growth and condition in Australian fur seals (Arctocephalus pusillus doriferus) (Carnivora: Pinnipedia). Aust J Zool 50:53-66

Ashmole NP (1963) The regulation of numbers of tropical oceanic birds. Ibis 103:458-473

Augé AA, Chilvers BL, Moore AB, Davis LS (2011) Foraging behaviour indicates marginal marine habitat for New Zealand sea lions: remnant versus recolonising populations. Mar Ecol Prog Ser 432:247-256

Back J, Hoskins AJ, Kirkwood R, Arnould JPY (2018) Behavioral responses of Australian fur seals to boat approaches at a breeding colony. Nat Conserv 31:35-52

Barnes MD, Craigie ID, Harrison LB, Geldmann J and others (2016) Wildlife population trends in protected areas predicted by national socio-economic metrics and body size. Nat Commun 7:12747

Baylis AMM, Tierney M, Staniland IJ, Brickle P (2018) Habitat use of adult male South American fur seals and a preliminary assessment of spatial overlap with trawl fisheries in the South Atlantic. Mamm Biol 93: 76-81

* Bevan E, Whiting S, Tucker T, Guinea M, Raith A, Douglas $R$ (2018) Measuring behavioral responses of sea turtles, saltwater crocodiles, and crested terns to drone disturbance to define ethical operating thresholds. PLOS ONE 13:e0194460

Born EW, Riget FF, Dietz R, Andriashek D (1999) Escape responses of hauled out ringed seals (Phoca hispida) to aircraft disturbance. Polar Biol 21:171-178

* Boyd I, McCafferty D, Reid K, Taylor R, Walker T (1998) Dispersal of male and female Antarctic fur seals (Arctocephalus gazella). Can J Fish Aquat Sci 55:845-852

*Buce E, Albright L, Sheehan S, Blewitt M (2014) Distribution patterns of migrating humpback whales (Megaptera novaeangliae) in Jervis Bay, Australia: a spatial analysis using geographical citizen science data. Appl Geogr 54: 83-95

Burleigh A, Lynch T, Rogers T (2008) Status of the Steamers Head (NSW) Australian and New Zealand fur seal haul-out site and influence of environmental factors and stochastic disturbance on seal behaviour. In: Lunney D, Munn A, Meikle W (eds) Too close for comfort: contentious issues in human-wildlife encounters. Royal Zoological Society of New South Wales, Mosman, p 246-254 
Cassini MH, Szteren D, Fernández-Juricic E (2004) Fence effects on the behavioural responses of South American fur seals to tourist approaches. J Ethol 22:127-133

* Caudron AK, Negro SS, Fowler M, Boren L, Poncin P, Robertson BC, Gemmell NJ (2009) Alternative mating tactics in the New Zealand fur seal (Arctocephalus forsteri): when non-territorial males are successful too. Aust J Zool 57:409-421

* Chapman BB, Brönmark C, Nilsson JÅ, Hansson LA (2011) The ecology and evolution of partial migration. Oikos 120:1764-1775

Chapron G, Kaczensky P, Linnell JDC, von Arx M and others (2014) Recovery of large carnivores in Europe's modern human-dominated landscapes. Science 346: 1517-1519

Ciucci P, Boitani L (1998) Wolf and dog depredation on livestock in central Italy. Wildl Soc Bull 26:504-514

炎Costalago D, Bauer B, Tomczak MT, Lundström K, Winder M (2019) The necessity of a holistic approach when managing marine mammal-fisheries interactions: Environment and fisheries impact are stronger than seal predation. Ambio 48:552-564

Cowling M, Kirkwood R, Boren L, Sutherland D, Scarpaci C (2015) The effects of vessel approaches on the New Zealand fur seal (Arctocephalus forsteri) in the Bay of Plenty, New Zealand. Mar Mamm Sci 31:501-519

Dudley N (2008) Guidelines for applying protected area management categories. IUCN, Gland

Dujon AM, Lindstrom RT, Hays GC (2014) The accuracy of Fastloc-GPS locations and implications for animal tracking. Methods Ecol Evol 5:1162-1169

* Duong T (2013) ks: Kernel smoothing. Version 1.8.13 https:// cran.r-project.org/src/contrib/Archive/ks/ks_1.8.13.tar.gz

Gales NJ, Mattlin RH (1998) Fast, safe, field-portable gas anesthesia for otariids. Mar Mamm Sci 14:355-361

* Garlepp L, Logan M, Kirkwood R (2014) Behavioral responses of Australian fur seals (Arctocephalus pusillus doriferus) to environmental variations. Mar Mamm Sci 30:978-993

Gerber LR, Hilborn R (2001) Catastrophic events and recovery from low densities in populations of otariids: implications for risk of extinction. Mammal Rev 31:131-150

Gompper ME, Belant JL, Kays R (2015) Carnivore coexistence: America's recovery. Science 347:382-383

Gormley AM, Slooten E, Dawson S, Barker RJ, Rayment W, du Fresne S, Bräger S (2012) First evidence that marine protected areas can work for marine mammals. J Appl Ecol 49:474-480

Granquist SM, Sigurjonsdottir H (2014) The effect of land based seal watching tourism on the haul-out behaviour of harbour seals (Phoca vitulina) in Iceland. Appl Anim Behav Sci 156:85-93

Guo Q, Taper M, Schoenberger M, Brandle J (2005) Spatialtemporal population dynamics across species range: from centre to margin. Oikos 108:47-57

Harasti D, Davis TR, Jordan A, Erskine L, Moltschaniwskyj $\mathrm{N}$ (2019) Illegal recreational fishing causes a decline in a fishery targeted species (snapper: Chrysophrys auratus) within a remote no-take marine protected area. PLOS ONE 14:e0209926

Harcourt RG, Bradshaw CJ, Davis LS (2001) Summer foraging behaviour of a generalist predator, the New Zealand fur seal (Arctocephalus forsteri). Wildl Res 28:599-606

Hardy N, Berry T, Kelaher BP, Goldsworthy SD and others (2017) Assessing the trophic ecology of top predators across a recolonisation frontier using DNA metabarcoding of diets. Mar Ecol Prog Ser 573:237-254

* Hodgson JC, Koh LP (2016) Best practice for minimising unmanned aerial vehicle disturbance to wildlife in biological field research. Curr Biol 26:R404-R405

*Holt RD (1987) Population dynamics and evolutionary processes: the manifold roles of habitat selection. Evol Ecol 1:331-347

*Hooker SK, Gerber LR (2004) Marine reserves as a tool for ecosystem-based management: the potential importance of megafauna. Bioscience 54:27-39

*Hooker SK, Cañadas A, Hyrenbach KD, Corrigan C, Polovina JJ, Reeves RR (2011) Making protected area networks effective for marine top predators. Endang Species Res 13:203-218

*Hoskins AJ, Schumann N, Costa DP, Arnould JPY (2017) Foraging niche separation in sympatric temperate-latitude fur seal species. Mar Ecol Prog Ser 566:229-241

*Huisamen J, Kirkman S, Watson L, Cockcroft V, Pistorius P (2011) Recolonisation of the Robberg Peninsula (Plettenberg Bay, South Africa) by Cape fur seals. Afr J Mar Sci 33:453-461

*Huon M, Jones EL, Matthiopoulos J, McConnell B, Caurant F, Vincent C (2015) Habitat selection of gray seals (Halichoerus grypus) in a marine protected area in France. J Wildl Manag 79:1091-1100

Irvine A, Bryden M, Corkeron P, Warneke R (1997) A census of fur seals at Montague Island, New South Wales. In: Hindell M, Kemper C (eds) Marine mammal research in the Southern Hemisphere: status, ecology and medicine. Surrey Beatty \& Sons, Chipping Norton, p 56-62

Karamanlidis AA, de Gabriel Hernando M, Krambokoukis L, Gimenez O (2015) Evidence of a large carnivore population recovery: counting bears in Greece. J Nat Conserv 27:10-17

Kelaher BP, Tan M, Figueira WF, Gillanders BM and others (2015) Fur seal activity moderates the effects of an Australian marine sanctuary on temperate reef fish. Biol Conserv 182:205-214

Kernaléguen L, Cherel Y, Knox TC, Baylis AMM, Arnould JPY (2015) Sexual niche segregation and gender-specific individual specialisation in a highly dimorphic marine mammal. PLOS ONE 10:e0133018

Kirkman SP (2010) The Cape fur seal: monitoring and management in the Benguela Current ecosystem. PhD thesis, University of Cape Town

Kirkwood R, Goldsworthy S (2013) Fur seals and sea lions. CSIRO Publishing, Collingwood

Kirkwood R, Boren L, Shaughnessy P, Szteren D and others (2003) Pinniped-focused tourism in the Southern Hemisphere: a review of the industry. In: Gales NJ, Hindell M, Kirkwood R (eds) Marine mammals: fisheries, tourism and management issues. CSIRO Publishing, Collingwood, p 257-276

* Kirkwood R, Lynch M, Gales N, Dann P, Sumner M (2006) At-sea movements and habitat use of adult male Australian fur seals (Arctocephalus pusillus doriferus). Can J Zool 84:1781-1788

K Kirkwood R, Pemberton D, Gales R, Hoskins AJ, Mitchell T, Shaughnessy PD, Arnould JPY (2010) Continued population recovery by Australian fur seals. Mar Freshw Res 61: 695-701

Knox TC, Baylis AMM, Arnould JPY (2017) Habitat use and diving behaviour of male Australian fur seals. Mar Ecol Prog Ser 566:243-256 
Kuhn CE, Baker JD, Towell RG, Ream RR (2014) Evidence of localized resource depletion following a natural colonization event by a large marine predator. J Anim Ecol 83:1169-1177

Lawton JH (1993) Range, population abundance and conservation. Trends Ecol Evol 8:409-413

Linnell JD, Nilsen E, Lande U, Herfindal I and others (2005) Zoning as a means of mitigating conflicts with large carnivores: principles and reality. In: Woodroffe R, Thirgood S, Rabinowitz A (eds) People and wildlife, conflict or coexistence? Book 9. Cambridge University Press, Cambridge, p 162-175

Lourie HJ, Hoskins AJ, Arnould JP (2014) Big boys get big girls: factors influencing pupping site and territory location in Australian fur seals. Mar Mamm Sci 30:544-561

Lowther AD, Harcourt RG, Page B, Goldsworthy SD (2013) Steady as he goes: at-sea movement of adult male Australian sea lions in a dynamic marine environment. PLOS ONE 8:e74348

Lundberg P (1988) The evolution of partial migration in birds. Trends Ecol Evol 3:172-175

* Lynch TP, Harcourt R, Edgar G, Barrett N (2013) Conservation of the critically endangered Eastern Australian population of the grey nurse shark (Carcharias taurus) through cross-jurisdictional management of a network of marine-protected areas. Environ Manag 52:1341-1354

* Magera AM, Flemming JEM, Kaschner K, Christensen LB, Lotze HK (2013) Recovery trends in marine mammal populations. PLOS ONE 8:e77908

* Marcella TK, Gende SM, Roby DD, Allignol A (2017) Disturbance of a rare seabird by ship-based tourism in a marine protected area. PLOS ONE 12:e0176176

* Marschall S, Granquist SM, Burns GL (2017) Interpretation in wildlife tourism: assessing the effectiveness of signage on visitor behaviour at a seal watching site in Iceland. J Outdoor Recreat Tour 17:11-19

* Martínez Cano I, Taboada FG, Naves J, Fernandez-Gil A, Wiegand T (2016) Decline and recovery of a large carnivore: environmental change and long-term trends in an endangered brown bear population. Proc R Soc B 283: 20161832

Mattlin RH (1978) Population biology, thermoregulation and site preference of the New Zealand fur seal, Arctocephalus forsteri, on the Open Bay Islands, New Zealand. PhD dissertation, University of Canterbury, Christchurch

McAllister JD, Barnett A, Lyle JM, Semmens JM (2015) Examining the functional role of current area closures used for the conservation of an overexploited and highly mobile fishery species. ICES J Mar Sci 72:2234-2244

* McCann T (1980) Territoriality and breeding behaviour of adult male Antarctic fur seal, Arctocephalus gazella. J Zool 192:295-310

McIntosh R, Sutherland D, Dann P, Kirkwood R and others (2014) Pup estimates for Australian and New Zealand fur seals in Victoria, Tasmania and New South Wales between 2007 and 2013. Report to The Australian Marine Mammal Centre, Department of the Environment, Hobart

McIntosh RR, Holmberg R, Dann P (2018a) Looking without landing - using remote piloted aircraft to monitor fur seal populations without disturbance. Front Mar Sci 5: 202

McIntosh RR, Kirkman SP, Thalman S, Southerland DR and others (2018b) Understanding meta-population trends of the Australian fur seal, with insights for adaptive monitoring. PLOS ONE 13:e0200253
McKenzie J, Page B, Goldsworthy SD, Hindell MA (2007a) Growth strategies of New Zealand fur seals in southern Australia. J Zool 272:377-389

McKenzie J, Page B, Shaughnessy PD, Hindell MA (2007b) Age and reproductive maturity of New Zealand fur seals (Arctocephalus forsteri) in southern Australia. J Mammal 88:639-648

Miller EH (1974) Social behaviour between adult male and female New Zealand fur seals, Arctocephalus forsteri during the breeding season. Aust J Zool 22:155-173

Miller JRB (2015) Mapping attack hotspots to mitigate human-carnivore conflict: approaches and applications of spatial predation risk modeling. Biodivers Conserv 24: 2887-2911

*Miller SD, McLellan BN, Derocher AE (2013) Conservation and management of large carnivores in North America. Int J Environ Stud 70:383-398

Morehouse AT, Boyce MS (2017) Troublemaking carnivores: conflicts with humans in a diverse assemblage of large carnivores. Ecol Soc 22:4

National Seal Strategy Group (2007) National strategy to address interactions between humans and seals: fisheries, aquaculture and tourism. Australian Government Department of Agriculture Fisheries and Forestry, Canberra

Niella Y, Smoothey AF, Peddemors V, Harcourt R (2020) Predicting changes in distribution of a large coastal shark in the face of the strengthening East Australian Current. Mar Ecol Prog Ser 642:163-177

NSW Marine Parks Authority (2010) Solitary Islands and Jervis Bay Marine Parks: research project summaries 2002-2009. New South Wales Marine Parks Authority, Hurtsville

*Page B, McKenzie J, Goldsworthy SD (2005) Dietary resource partitioning among sympatric New Zealand and Australian fur seals. Mar Ecol Prog Ser 293:283-302

*Page B, McKenzie J, Sumner MD, Coyne M, Goldsworthy SD (2006) Spatial separation of foraging habitats among New Zealand fur seals. Mar Ecol Prog Ser 323:263-279

*Pérez-Jorge S, Pereira T, Corne C, Wijtten Z and others (2015) Can static habitat protection encompass critical areas for highly mobile marine top predators? Insights from coastal East Africa. PLOS ONE 10:e0133265

*Pato G, Guidetti P, Bartolini F, Mangialajo L, Francour P (2013) The importance of high-level predators in marine protected area management: consequences of their decline and their potential recovery in the Mediterranean context. Adv Oceanol Limnol 4:176-193

R Development Core Team (2012) R: a language and environment for statistical computing. R Foundation for Statistical Computing, Vienna

Koberts KE, Valkan RS, Cook CN (2018) Measuring progress in marine protection: a new set of metrics to evaluate the strength of marine protected area networks. Biol Conserv 219:20-27

* Robertson BC, Chilvers BL, Duignan PJ, Wilkinson IS, Gemmell NJ (2006) Dispersal of breeding, adult male Phocarctos hookeri: implications for disease transmission, population management and species recovery. Biol Conserv 127:227-236

* Robinson S, Gales R, Terauds A, Greenwood M (2008a) Movements of fur seals following relocation from fish farms. Aquat Conserv 18:1189-1199

* Robinson S, Terauds A, Gales R, Greenwood M (2008b) Mitigating fur seal interactions: relocation from Tasmanian aquaculture farms. Aquat Conserv 18:1180-1188 
Santini L, Boitani L, Maiorano L, Rondinini C (2016) Effectiveness of protected areas in conserving large carnivores in Europe. In: Joppa LN, Baillie JEM, Robinson JG (eds) Protected areas: Are they safeguarding biodiversity? John Wiley \& Sons, Chichester, p 122-133

Schumann N, Gales NJ, Harcourt RG, Arnould JP (2013) Impacts of climate change on Australian marine mammals. Aust J Zool 61:146-159

Shaughnessy PD, Goldsworthy SD (2015) Long-nosed fur seal: a new vernacular name for the fur seal, Arctocephalus forsteri, in Australia. Mar Mamm Sci 31: 830-832

Shaughnessy P, Kirkwood R, Cawthorn M, Kemper C, Pemberton D (2003) Pinnipeds, cetaceans and fisheries in Australia: a review of operational interactions. In: Gales N, Hindell M, Kirkwood R (eds) Marine mammals: fisheries, tourism and management issues. CSIRO Publishing, Melbourne, p 136-152

Shaughnessy PD, Nicholls AO, Briggs SV (2008) Do tour boats affect fur seals at Montague Island, New South Wales? Tour Mar Environ 5:15-27

Shaughnessy P, Goldsworthy S, Mackay A (2015) The longnosed fur seal (Arctocephalus forsteri) in South Australia in 2013-14: abundance, status and trends. Aust J Zool 63:101-110

Shivik JA (2004) Non-lethal alternatives for predation management. Sheep Goat Res J 19:64-71

Stahl P, Vandel J, Herrenschmidt V, Migot P (2001) The effect of removing lynx in reducing attacks on sheep in the French Jura Mountains. Biol Conserv 101:15-22

Staniland IJ, Robinson SL (2008) Segregation between the sexes: Antarctic fur seals, Arctocephalus gazella, foraging at South Georgia. Anim Behav 75:1581-1590

Stevens MA, Boness DJ (2003) Influences of habitat features and human disturbance on use of breeding sites by a declining population of southern fur seals (Arctocephalus australis). J Zool (Lond) 260:145-152

Stirling I (1970) Observations on the behavior of the New Zealand fur seal (Arctocephalus forsteri). J Mammal 51: 766-778

Stoms DM, Davis FW, Andelman SJ, Carr MH and others (2005) Integrated coastal reserve planning: making the land-sea connection. Front Ecol Environ 3:429-436

Suthers IM, Young JW, Baird ME, Roughan M and others (2011) The strengthening East Australian Current, its eddies and biological effects - an introduction and overview. Deep Sea Res II Top Stud Oceanogr 58:538-546

Tarjan LM, Tinker MT (2016) Permissible home range esti-

Editorial responsibility: Clive McMahon,

Hobart, Tasmania, Australia

Reviewed by: 3 anonymous referees mation (PHRE) in restricted habitats: a new algorithm and an evaluation for sea otters. PLOS ONE 11:e0150547

Thackway R, Cresswell ID (1997) A bioregional framework for planning the national system of protected areas in Australia. Nat Areas J 17:241-247

Treves A (2009) Hunting for large carnivore conservation. J Appl Ecol 46:1350-1356

Treves A, Karanth KU (2003) Human-carnivore conflict and perspectives on carnivore management worldwide. Conserv Biol 17:1491-1499

Trouwborst A, Krofel M, Linnell JD (2015) Legal implications of range expansions in a terrestrial carnivore: the case of the golden jackal (Canis aureus) in Europe. Biodivers Conserv 24:2593-2610

Wand MP, Jones MC (1994) Multivariate plug-in bandwidth selection. Comput Stat 9:97-116

Warneke RM (1975) Dispersal and mortality of juvenile fur seals Arctocephalus pusillus doriferus in Bass Strait, southeastern Australia. Rapp P-V Reun Cons Int Explor Mer 169:296-302

Warneke R, Shaughnessy P (1985) Arctocephalus pusillus, the South African and Australian fur seal: taxonomy, evolution, biogeography, and life history. In: Ling JK, Bryden $M$ (eds) Studies of sea mammals in south latitudes. South Australian Museum, Adelaide, p 53-77

W Watson D, Beaven B, Bradshaw C (2015) Population trends of New Zealand fur seals in the Rakiura region based on long-term population surveys and traditional ecological knowledge. N Z J Mar Freshw Res 49:106-118

Watson H, Bolton M, Monaghan P (2014) Out of sight but not out of harm's way: human disturbance reduces reproductive success of a cavity-nesting seabird. Biol Conserv 174:127-133

Watson JE, Dudley N, Segan DB, Hockings M (2014) The performance and potential of protected areas. Nature 515:67-73

W Wcisel M, O'Riain MJ, de Vos A, Chivell W (2015) The role of refugia in reducing predation risk for Cape fur seals by white sharks. Behav Ecol Sociobiol 69:127-138

*Wirsing AJ, Heithaus MR, Dill LM (2007) Living on the edge: dugongs prefer to forage in microhabitats that allow escape from rather than avoidance of predators. Anim Behav 74:93-101

Woodroffe R, Thirgood S, Rabinowitz A (2005) The future of coexistence: resolving human-wildlife conflicts in a changing world. In: Woodroffe R, Thirgood S, Rabinowitz A (eds) People and wildlife, conflict or co-existence? Cambridge University Press, Cambridge, p 388-405

Submitted: October 27, 2020

Accepted: April 6, 2021

Proofs received from author(s): June 16, 2021 